velopment of critical thinking and values, for interdisciplinary studies for all, for campus environment, for service and immersion experiences, for community.

Our mission today clearly has implications, too, for staffing. It is obvious, and has been obvious for many years, that our educational institutions could not survive without the presence and assistance of many dedicated lay people. We have been blessed by God with many lay people who have shared our vision and our principles, and have worked in our institutions with real dedication. As time goes on, however, we need to do more-in the selection of professors, administrative staff and members of Boards, and especially in ongoing formation for both Jesuits and lay people in order to create an educational community united in mission. All too often we have seen cases where new lay colleagues are welcomed intoJesuit faculties solely on the basis of academic or other professional credentials. Unless there is a prior clarity concerning a statement of the mission of the institution, and a prior acceptance and commitment to foster this mission, it seems unrealistic to expect that we can hope for an institution to continue "in the Ignatian tradition." And growth in understanding and commitment needs to be cultivated through faculty seminars, discussions and the like, as well as through individual conversations and friendships. Clearly, opportunities for closer involvement in sharing in the spirit and mission of the institution should be offered through colloquia, retreats, and liturgies for those who are open to and desirous of them. This is not a case of too few Jesuits needing to seduce the laity into acting likeJesuits. That thinking is not worthy of us. Rather the many views of all members of the higher education community who follow Ignatius with their own perspectives must come together to affect the university's life and developing Ignatian tradition.

In briefly describing some issues that confront us, it becomes clear that the challenge Jesuit universities face is not easy. But it has always been a hallmark of the Jesuit tradition that we work at the growing edge of human and apostolic developments. This is rooted in the motto of the Society of Jesus, which rejects complacency and mediocrity. It calls us all to work for others to the greater glory of God, Ad Majorem Dei Gloriam.

\section{TRENDS In JAPANESE Higher EDUCATION}

\section{William Currie, S.J.}

Williom Currie, S.J. is Dean, Faculty of Comparative Culture, Sophio University, 7 Kiocho, Chiyoda-ku, Tokyo 102, JAPAN Fox: 81-33-238-5056

$\mathrm{R}$ eform is a word frequently heard in discussions reated to higher education in Japan these days. In recent years, throughout the country university educators are going through a process of trying to respond to the call for educational reform submitted to the prime minister in 1987 by the National Council on Educational Reform. The fact that the final report of the council was submitted in 1987 and most of the responses are still in the talking stage indicates just how conservative and slow to change is the university community as a whole in this country.

Part of the slowness to translate into action concrete plans for university reform is due to the fact that two of the principle goals suggested by the council seem to be at odds with each other. On the one hand, universities have been admonished to raise the level of research so that Japanese institutions of higher learning can compete with any other equivalent institutions on an international level. On the other hand, university educators have been encouraged to make higher education available to larger numbers of people, including older citizens in this rapidly aging society. Japanese society has traditionally been known as a gakureki society, meaning that one's employment possibilities and prospects for promotion depend greatly on the prestige of the university from which one graduated. Attempts to make education at hitherto "elite" universities available to a broader audience seems to run counter to the attempts to concentrate on higher research.

Educators are talking these days about the need for each university to have a distinguishing character of its own in order to appeal to the dwindling eighteen-year-old population. This sometimes means in fact that some universities are putting renewed emphasis on research and beefing up graduate programs, while other universities are looking to more popular undergraduate programs (anything related to information sciences attracts candidates these days) in order to draw on the pool of nontraditional students. Policymaking decisions within individual universities on whether to place miore importance on undergraduate or graduate education can occasionally become controversial and divisive.

The major crisis facing Japanese universities today is the financial one. The second wave of haby-boomess has already entered the university, and the number of eighteenyear-olds in Japan began to decline rapidly as $\boldsymbol{o}$ fone year ago. Even the most prestigious private universities in the 
country have seen a decline in applicants stamng last year, and a number of national and public institutions as well are suffering from a similar decline. With a decline in student population, universities are having difficulty meeting rising personnel costs without raising tuition. And raising the already high tuition costs discourages students from applying, especially in these times of continuing recession. This vicious circle is the biggest headache within higher education today.

Jesuit institutions of higher education in Japan are responding to the same challenges and developmentsinJapanese society, but also to added problems related to the effort to maintain a Catholic and specificallyJesuit identity. For instance, the average age of Jesuit faculty members teaching at Sophia University has been rising steadily, and this spring nine more Jesuit educators have reached the mandatory retirement age of 70 . This leaves a total of 70 Jesuits teaching in the seven faculties of the university, with a student population of 10,500 undergraduates and 1,000 graduate students. As the number of teaching Jesuits slowly declines, the problem of preserving the Jesuit identity of the university becomesmore and more challenging. A question of priorities becomes more pressing, as Jesuits connected with the university try to make decisions as to which faculties should receive special focus when considering replacements for the dwindlingJesuit manpower. In a related problem, up until now foreign languages and foreign literatures have been among the university's strongest areas, and ever since Sophia's founding in 1913,Jesuits of many different nationalities have been the native speakers and experts providing the backbone for these disciplines. Professors in these fields can certainly he found as replacements, but how to maintain a Jesuit presence is rapidly becoming a critical problem.

The question mentioned above about whether to emphasize a strong program of graduate research or undergraduate education is currently being discussed at Sophia University also. Traditionally, Sophia has provided a high level of graduate programs, with doctoral studies in 24 disciplines. Maintaining this tradition while at the same time continuing a solid undergraduate program that provides not only general and specialized education but a formation according to the ideals of Christian humanism is not a simple task. As Jesuit numbers decrease, it becomes more difficult.

One of the attractive features of Sophia University has traditionally been its low student-teacher ratio, which compares favorably with other Japanese universities. If the financial crisis mentioned above continues, it will become more and more difficult to preserve a ratio favorable to the students, without a considerable rise in tuition fees.

In order to continue as a specifically Catholic university, some have urged that Sophia should allow special admittance for students from Catholic high schools, hut this suggestion is rather controversial. Already a special recommendation system has been established with the four Jesuit high schools inJapan, and this system has not always met with the unanimous approval of all faculty members.

There is one area in which Sophia University, among all the national, public, or private universities in Japan, stands in the most advantageous position to meet the needs of the times as outlined by the National Council on Educational Reform. That is the area of internationalization. Sophia has in any given year, 750 non-Japanese students from more than 60 nationalities studying on its campuses, and 107 foreign teachers from 22 countries. Sophia students studying abroad on exchange programs usually number about 150 per year, and that number is growing. One campus of the university houses the Faculty of Comparative Culture, where all courses are taught in English for the benefit of foreign students not yet fluent in the Japanese language.

It is still too early to tell what concrete reforms will be put into effect to meet the current challenges facing Japanese higher education as we reach the end of the 20th century We can hope, however, that Jesuit educators in Japan will continue to work together with their colleagues in the university community to read the signs of the times and come up with innovations that reflect the tradition of Jesuit education throughout the world.

\section{Some Current Developments IN INDIA's HIGHER EDUCATION}

\section{N. K. Uberoi}

N.K. Uberoi is director, Center for Professional Development in Higher Education, Delhi University, Delhi 110007 India.

Te Challenge to Education (1985). a document pro-
duced by the Ministry of Education of the Indian Government states that "the whole process of higher education has become warped, disoriented and dysfunctional, producing a number of unemployable young men and women." It may appear odd to quote this as an opening statement of an essay on India's higher education system, but there is no other objective way of introducing the subject. The statement and what follows refer to postsecondary college and university systems, and excludes nonuniversity and professional institutions of higher education. In India, higher education is faced with deteriorating conditions resulting from expansion and worsened by an affiliation system and shrinking resources. Lately, these and other issues, such as declining quality, inadequate facilities, and a mismatch between education and human power requirements, have become crucial themes in current social and political debate. However, this is nothing new $\rightarrow$ number of edu- 